\title{
GESTÃO AMBIENTAL: UMA ANÁLISE DA EVIDENCIAÇÃO DAS EMPRESAS QUE COMPÕEM O ÍNDICE DE SUSTENTABILIDADE EMPRESARIAL (ISE)
}

\author{
Júlio Orestes da Silva ${ }^{1}$ \\ Irani Rocha ${ }^{2}$ \\ Paulo Wienhage ${ }^{3}$ \\ Rita Buzzi Rausch ${ }^{4}$
}

\begin{abstract}
RESUMO
Essa pesquisa buscou analisar as informações relacionadas à gestão ambiental mais evidenciadas nos relatórios de administração e notas explicativas das empresas que compõem o Índice de Sustentabilidade Empresarial (ISE). Para tal, optou-se por uma pesquisa documental descritiva, com abordagem qualitativa, por meio de análise de conteúdo. A amostra constitui-se de todas as empresas que compõem o Índice de Sustentabilidade Empresarial 2009/2010 da BOVESPA, totalizando 29 empresas. Constatou-se nas análises realizadas que a evidenciação ambiental destacou-se em 128 observações, que correspondem a $12 \%$ do total possível de evidenciação ambiental com base no modelo proposto. Ressalta-se ainda que as informações de gestão ambiental mais evidenciadas referem-se a "Resíduos" e a "Energia", porém por serem empresas que fazem parte de um índice que considera questões ambientais na escolha das empresas participantes, compreende-se que a evidenciação de informações de gestão ambiental deva ser mais comumente explicitada nos relatórios, que servem como fontes de informação na tomada de decisão dos diversos usuários.
\end{abstract}

Palavras-chave: Gestão Ambiental. Evidenciação. Índice de Sustentabilidade Empresarial.

\section{ABSTRACT}

This research investigates the information related to environmental management more evident in reports of management and notes of the companies that compose the Corporate Sustainability Index (CSI). For this purpose, a descriptive documental analysis was chosen, with qualitative method, using content analysis. The sample consisted of all the companies that compose the Corporate Sustainability Index of BOVESPA 2009/2010, comprehending 29 companies. It was found that the environmental disclosure noted in 128 observations, which represent $12 \%$ of the possible total amount of environmental disclosure based on the proposed model. It was noted that the more evident information on environmental management refer to "waste" and "Energy", but because they are companies that are part of an index that considers environmental issues in the choice of participating companies, it is understood that disclosure

1 Mestrando do Programa de Pós-Graduação em Ciências Contábeis da Universidade Regional de Blumenau - Furb. E-mail: juliosilva@al.furb.br

${ }^{2}$ Mestranda do Programa de Pós-Graduação em Ciências Contábeis da Universidade Regional de Blumenau - Furb. E-mail: irocha@al.furb.br

3 Mestrando do Programa de Pós-Graduação em Ciências Contábeis da Universidade Regional de Blumenau - Furb. E-mail: pwienhage@hotmail.com

${ }^{4}$ Doutora em Educação Professora do Programa de Pós-Graduação em Ciências Contábeis da Universidade Regional de Blumenau - Furb. E-mail: rausch@furb.br 
of information of environmental management must be more clearly demonstrated in the reports, which serve as sources of information in decision-making of different users.

Keywords: Environmental Management. Disclosure. Sustainability Index.

\section{INTRODUÇÃO}

A preocupação com o meio ambiente, a responsabilidade social, práticas de governança corporativa entre outras medidas, estão contribuindo cada vez mais para uma crescente demanda dentro do mercado financeiro direcionada aos produtos voltados a esse nicho (Rezende, Nunez e Portela, 2008). Nesse sentido, Azevedo e Cruz (2006) destacam que as empresas, cada vez mais, sofrem cobrança da sociedade quanto à prestação de contas no sentido de identificar aquelas entidades que geram prejuízos ou que não acrescentam nenhum valor à qualidade de vida da comunidade onde estão inseridas.

De acordo com Rover, Borba e Borgert (2008), os impactos que as empresas causam ao meio ambiente acabam refletindo no mercado que atuam e na imagem da organização perante a opinião pública. Devido a essa situação, a questão ambiental está sendo incorporada nas companhias por meio de seus relatórios, adotando sistemas de gestão ambiental e investindo em procedimentos que reduzam os impactos que suas atividades causam ao meio ambiente. Assim, Calixto (2006) destaca que a divulgação voluntária das ações sociais e ambientais por meio dos relatórios contábeis tem sido uma prática comum em empresas de diversos setores a partir da década de 1990.

A divulgação das informações por meio dos relatórios da empresa pode ser observada a partir da evidenciação. Aquino e Santana (1992) destacam que evidenciar significa divulgar as informações com clareza, de maneira que se compreenda imediatamente o que está sendo comunicado. Nesse sentido, para Ponte e Oliveira (2004), existem diferentes formas de evidenciar, mas as informações devem ser com qualidade e quantidade que atendam às necessidades dos usuários das demonstrações contábeis. A evidenciação de informação ambiental tem sido muito debatida na literatura acadêmica, no qual procura-se observar a relevância do tema nos relatórios apresentados pelas empresas.

Devido à relevância da questão meio ambiente nas organizações e buscando atender às novas exigências do mercado, a Bolsa de Valores de São Paulo (BOVESPA), juntamente com várias instituições uniram esforços para criar um índice de ações para servir de referência aos investidores socialmente responsáveis, surgindo então o Índice de Sustentabilidade Empresarial (ISE) (BOVESPA, 2009). A Bovespa (2009) considera Índice de Sustentabilidade Empresarial "um índice que mede o retorno total de uma carteira teórica composta por ações de empresas com reconhecido comprometimento com a responsabilidade social e a sustentabilidade empresarial (no máximo 40)”. Neste sentido, esta pesquisa aborda o tema evidenciação ambiental nos relatórios das empresas do índice de Sustentabilidade Empresarial da Bolsa de Valores de São Paulo. Essa pesquisa procurou responder a seguinte questão: Quais as informações mais evidenciadas pelas empresas que compõem o Índice de Sustentabilidade Empresarial (ISE) relacionadas à gestão ambiental?

Por conseguinte, o artigo procura analisar as informações relacionadas á gestão ambiental mais evidenciadas nos relatórios de administração e notas explicativas das empresas que compõe o Índice de Sustentabilidade Empresarial (ISE). No que tange ao relatório administrativo, Burlin et al (2001) destaca que “o relatório da administração por apresentar-se de modo descritivo e não de uma forma técnica, como ocorre nos outros relatórios, possibilita o entendimento para um maior número de usuários, pois tem um poder maior de comunicação”. 
O presente estudo é organizado da seguinte maneira: além desta seção de caráter introdutório, as seções 2, 3 e 4 apresentam o referencial teórico, abordando evidenciação da informação ambiental, gestão ambiental e o conceito de ISE. Na seção 5 apresentam-se o método e procedimentos da pesquisa. Na seção 6 a análise dos dados e por último, na seção 7 , as considerações finais.

\section{EVIDENCIAÇÃO DA INFORMAÇÃO AMBIENTAL}

Iudícibus (1997) destaca que a evidenciação faz parte dos objetivos da Contabilidade. Nesse sentido, Ribeiro (2005, p.45) destaca que o objetivo da evidenciação é "identificar, mensurar e esclarecer os eventos e transações econômico-financeiros que estejam relacionados com a proteção, preservação, e recuperação ambiental, ocorridos em um determinado período, visando à evidenciação da situação patrimonial da entidade”. Sendo assim, existem várias formas de evidenciar, focando um único objetivo, apresentar informação quantitativa e qualitativa de maneira ordenada a fim de proporcionar uma base adequada de informações para o usuário (Iudícibus, 1997). Corroborando com esses autores, Souza e Ribeiro (2004) destacam que cabe a contabilidade evidenciar as atividades da empresa com relação ao meio ambiente, por meio de elaboração e fornecimento de informações aos usuários internos e externos. Informações essas que possam causar modificações na situação patrimonial da entidade.

A evidenciação de informação ambiental tem sido muito debatida na literatura acadêmica, em que se procura observar a relevância do tema nos relatórios apresentados pelas empresas como observa-se nos estudos realizados por: Oliveira e Ribeiro (2003), Campbell (2004), Borba, Alves e Rover (2005), Calixto e Mendonça (2006), Azevedo e Cruz (2007), Garcia et al (2008) e Rover et al (2009).

Oliveira e Ribeiro (2003) buscaram em seus estudos analisar a evolução da evidenciação das informações ambiental da empresa Petrobrás durante o período de três anos. Os autores observaram uma evolução ano a ano com relação a evidenciação ambiental, ou seja, a empresa vem evidenciando cada vez mais essas informações.

Campbell (2004) procurou analisar a quantidade de informações voluntárias divulgadas referentes ao meio ambiente, nos relatórios anuais de algumas companhias britânicas. Os resultados do estudo demonstraram que ocorreu um aumento na divulgação de informações ambientais das empresas analisadas, principalmente a partir da década de 1980.

No estudo abordado por Borba, Alves e Rover (2005) foi investigado as distintas práticas de evidenciação ambiental nas demonstrações contábeis de companhias brasileiras submetidas à Comissão de Valores Mobiliários (CVM) e à Securities and Exchange Commission (SEC). Foi possível concluir que nas informações publicadas conforme as normas da SEC o objetivo é mensurar e reconhecer o impacto de determinados fatos contábeis sobre o patrimônio da organização e que nas publicações junto à CVM tais evidenciações são de caráter publicitário.

Calixto e Mendonça (2006) procuraram observar a relação entre as notícias desfavoráveis referente ao meio ambiente divulgadas pela mídia impressa brasileira com as notícias favoráveis divulgadas nos relatórios contábeis de uma companhia de grande porte. Os autores concluíram quanto ao relacionamento da companhia com o meio ambiente que as informações divulgadas nos relatórios contábeis não estão relacionadas diretamente com as informações divulgadas pela mídia impressa brasileira, devido à fraca correlação encontrada. Quanto ao nível de divulgação de informações sobre o meio ambiente nos relatórios da empresa não estão associados fortemente com o nível de notícias desfavoráveis divulgadas na mídia impressa brasileira. Nesse sentido, para que a companhia divulgue informações sobre a sua gestão ambiental por meio dos seus demonstrativos contábeis, entende-se que outros fatores sejam determinantes. 
Azevedo e Cruz (2007) procuraram em seus estudos investigar o nível de evidenciação das informações de natureza sócio-ambiental divulgadas pelas distribuidoras de energia elétrica que atuam na região Nordeste do Brasil. Dentre os resultados alcançados, destacam que as atividades desenvolvidas por empresas do setor elétrico causam significativos impactos sociais e ambientais, justificando dessa maneira a exigência de publicação do balanço social por parte da empresas desse setor.

Garcia et al (2008) em seu estudo investigaram se as empresas que fazem parte do Índice de Sustentabilidade Empresarial da Bolsa de Valores de São Paulo (ISE) com objetivos de atender a sustentabilidade empresarial, na prática, utilizam o referencial teórico da Contabilidade Ambiental. Os autores observaram em seu estudo pouco conhecimento sobre o que é Contabilidade Ambiental. Observou-se uma grande preocupação com a imagem das empresas frente ao mercado e a sociedade no sentido de reputação e marketing.

Rover et al (2009) buscaram em seus estudos identificar os fatores determinantes da divulgação voluntária ambiental por empresas brasileiras potencialmente poluidoras. Para realização do estudo foram analisados demonstrativos financeiros padronizados (DFPs) e os relatórios de sustentabilidade (RS) das empresas abertas com ações listadas na bolsa de valores de São Paulo (Bovespa) do período de 2005 a 2007. Os autores concluíram que nos três anos analisados, as empresas evidenciaram um total de 6.182 sentenças ambientais, sendo $73 \%$ divulgadas nos RS e 27\% nas DFPs. A análise de regressão em painel demonstrou que as variáveis: tamanho da empresa, sustentabilidade, empresa de auditoria e publicação do RS são relevantes a um nível de significância de 5\% para explicar o disclosure voluntário de informações ambientais.

\section{GESTÃO AMBIENTAL}

Devido às transformações no contexto empresarial, muitas organizações têm a consciência que para alcançar um bom desempenho e se manter no mercado de hoje, a sua responsabilidade social não pode ser ignorada, sendo necessário integrá-la em sua estratégia empresarial (Gonçalves e Heliodoro, 2005). Nesse sentido, a responsabilidade da empresa com relação ao meio ambiente está em evidência. Dessa forma, os acionistas, investidores, bancos e os consumidores estão cada vez mais exigentes, fazendo com que as organizações sintam-se pressionadas a reduzirem o risco ambiental (Souza, 2002).

Conforme Andrade, Tachizawa e Carvalho (2002), em grandes empresas os gastos com proteção ambiental começam a serem vistos, não como custo e sim como investimentos no futuro e consequentemente como vantagem competitiva. Corroborando com o autor, Wernke (2001) destaca que a variável ambiental é um dos diferenciais que propicia a empresa sua relevância no mercado, estar à frente de outras empresas dessa maneira e se destacar.

Com o objetivo de incorporar na gestão empresarial os conceitos e compromissos que propiciem o desenvolvimento sustentável das organizações, o Instituto Ethos (2009), organização não-governamental, desenvolveu uma série de indicadores de responsabilidade social. Entre eles, desenvolveu alguns indicadores para mensurar o aspecto referente ao meio ambiente: a) compromisso com a melhoria da qualidade ambiental; b) educação e conscientização ambiental; c) gerenciamento dos impactos sobre o meio ambiente e do ciclo de vida de produtos e serviços; d) sustentabilidade da economia florestal e e) minimização de entradas e saídas de materiais (Silveira, 2008). Na Figura 1 apresenta-se as categorias e seus respectivos indicadores (INSTITUTO ETHOS, 2009). 


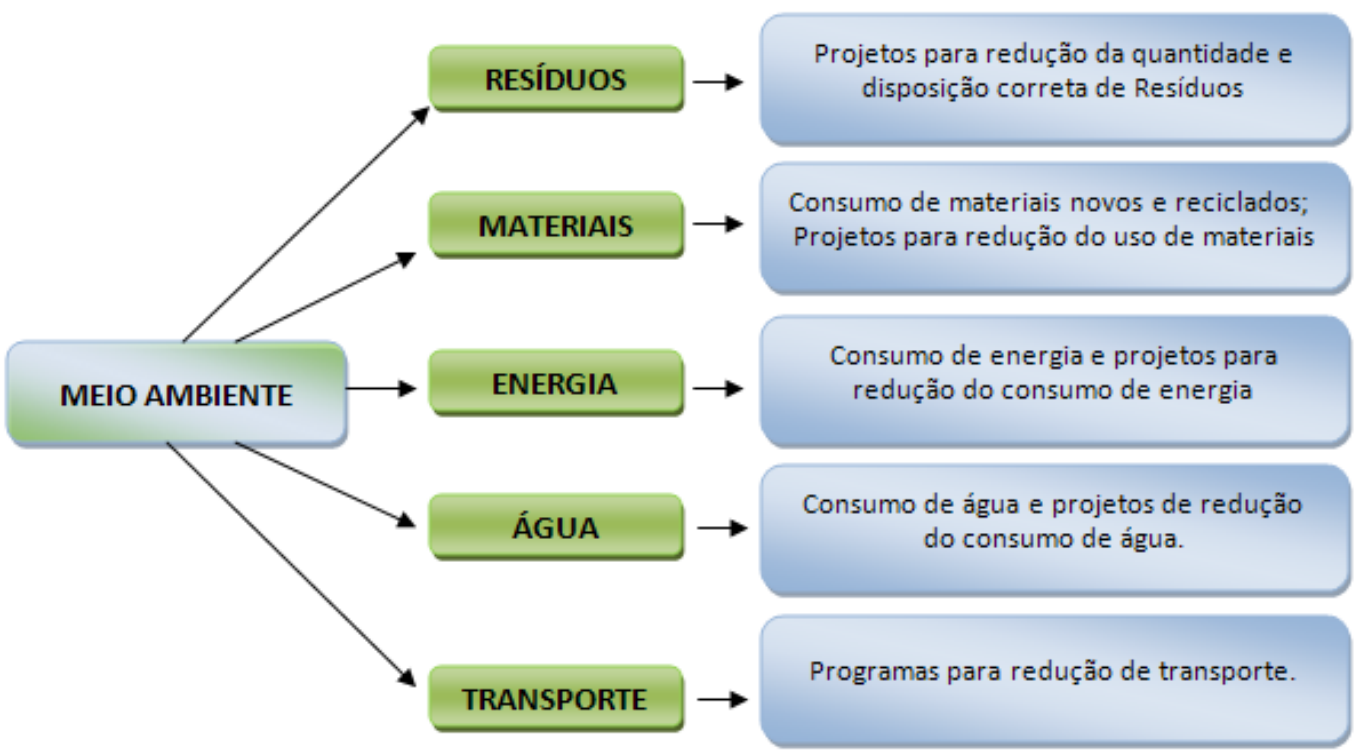

Figura 1 - Mapa de Gestão Ambiental - Meio Ambiente

Fonte: Adaptado do Instituto Ethos (2009)

Observa-se na Figura 1 a definição de cinco categorias para mensurar o compromisso da organização com relação ao meio ambiente, ou seja, demonstrando ações de educação ambiental, minimização no descarte de resíduos, forma de utilização de recursos naturais não renováveis (como consumo de energia e água), participação de materiais usados provenientes de reciclagem e reutilização de materiais.

De acordo com Valle (2004), os resíduos representam um dos maiores riscos ambientais, mas, considera-se interessante destacar que o resíduo não é algo nocivo. Ele pode ser transformado em subprodutos ou matérias primas para outras linhas de produção. Corroborando com o autor, Moreira (2006) destaca que a preocupação com relação aos resíduos está relacionada à disposição inadequada, geração acelerada e o esgotamento da capacidade de aterro.

Já no aspecto energia, Moreira (2006) considera que as principais preocupações nesse aspecto estão ligadas à redução do uso deste bem fornecido por fontes não renováveis (petróleo, gás e carvão), em contrapartida, ao desenvolvimento de fontes alternativas de geração de energia de forma que se evite a construção de novas usinas hidrelétricas e nucleares. Nesse sentido, a energia é um insumo importante em praticamente todos os produtos consumidos pela população, consequentemente, a utilização da energia está diretamente ligada à qualidade de vida da humanidade (Moura, 2008).

Com relação à água, Moreira (2006) destaca que esse indicador representa a preocupação com a contaminação dos oceanos, a qualidade de água e manutenção da vida terrestre. Infere-se que, 74\% da superfície terrestre é composta por água, mas, apenas 0,8\% está disponível para o consumo humanidade.

Assim, referente ao transporte a preocupação está com relação aos poluentes do ar, esses poluentes deverão ser controlados porque interferem diretamente na qualidade de vida, gerando doenças entre outras conseqüências (Moura, 2008).

No intuito de contribuir para a ampliação desta discussão, este estudo busca analisar as informações relacionadas à gestão ambiental mais evidenciadas nos relatórios de administração e notas explicativas das empresas que compõe o Índice de Sustentabilidade Empresarial (ISE). Espera-se que esta análise possa contribuir com os estudos referente ao 
tema em questão, possibilitando uma maior reflexão sobre a atuação da Contabilidade como ferramenta de controle social.

\section{4 ÍNDICE DE SUSTENTABILIDADE EMPRESARIAL - ISE}

O conceito de sustentabilidade representa para o setor empresarial uma nova abordagem de se fazer negócios que promove a responsabilidade social, reduz o uso de recursos naturais, reduzindo consequentemente, os impactos negativos sobre o meio ambiente, preservando a integridade do planeta para as futuras gerações, sem deixar de lado a rentabilidade econômico-financeira do empreendimento. Esta abordagem juntamente com as melhores práticas de governança corporativa, corrobora para o desenvolvimento sustentável ao mesmo tempo em que cria valor ao acionista e proporciona maior probabilidade de continuidade do negócio no longo prazo (BOVESPA, 2009). Nesse sentido, as empresas que objetivam captar novos investidores, passaram a divulgar além das informações obrigatórias, informações adicionais a respeito da gestão empresarial e ações de responsabilidade social e ambiental. As informações voluntárias podem ser tanto de natureza financeira com não financeira. (Vaz et al., 2008).

Buscando atender as novas exigências do mercado, a Bolsa de Valores de São Paulo (BOVESPA), juntamente com várias instituições, uniram esforços para criar um índice de ações para servir de referência aos investidores socialmente responsáveis, surgindo então o Índice de Sustentabilidade Empresarial (ISE) (BOVESPA, 2009). O Índice de Sustentabilidade Empresarial foi criado em meados de 2005, tendo como conceito básico Triple Botton Line (TBL), juntamente com critérios de governança corporativa, seguindo o índice da Bolsa de Johannesburg (JSE). O propósito da ISE é ser um ambiente de investimento e despertar a responsabilidade ética das corporações (Rezende e Santos, 2006).

A Bovespa (2009) considera Índice de Sustentabilidade Empresarial “um índice que mede o retorno total de uma carteira teórica composta por ações de empresas com reconhecido comprometimento com a responsabilidade social e a sustentabilidade empresarial (no máximo 40).” Para tanto, são selecionadas as ações mais negociadas na Bovespa no que tange a liquidez, sendo ponderadas na carteira pelo valor de mercado das ações disponíveis à negociação.

O critério para seleção das empresas é por meio de questionários que são avaliados e analisados por agências e ou empresas especializadas, que consolidam, organizam e conferem as informações prestadas pelas empresas (Gonçalves, Pirani e Borger, 2007). Na sequência, a escolha das empresas que apresentam a melhor classificação é feita pelo conselho deliberativo, presidido pela Bovespa. A avaliação envolve elementos ambientais, sociais e econômico-financeiros, acrescidos mais três grupos de indicadores: a) critérios gerais; b) critérios de natureza do produto; e c) critérios de governança corporativa. Cabe ressaltar ainda que o preenchimento do questionário (com apenas perguntas objetivas) é voluntário, demonstrando o comprometimento da empresa com as questões de sustentabilidade, consideradas cada vez mais importantes no mundo todo (BOVESPA, 2009).

\section{MÉTODOS E PROCEDIMENTOS DA PESQUISA}

O presente estudo utiliza uma abordagem descritiva. Segundo Triviños (1987) o estudo descritivo requer delimitações de técnicas, métodos, modelos e teorias. Para Raupp e Beuren (2008, p. 81): “a pesquisa descritiva configura-se como um estudo intermediário entre a pesquisa exploratória e a explicativa, ou seja, não é tão preliminar como a primeira e não tão aprofundada como a segunda”. Quanto aos procedimentos, caracteriza-se como pesquisa documental. Para Beuren (2008), as pesquisas documentais utilizam materiais que não recebem análise, mas que podem ser reelaborados de acordo com os objetivos da pesquisa. $\mathrm{O}$ 
estudo é documental porque utilizou relatórios da administração (RA) e notas explicativas (NE) como fontes de dados para análise.

Quanto à abordagem do problema, classifica-se como qualitativa. Richardson (1989, p. 38) destaca que a abordagem qualitativa "difere, em princípio, do quantitativo à medida que não emprega um instrumental estatístico como base do processo de análise”. É qualitativa porque procurou verificar as informações relacionadas à gestão ambiental evidenciadas nos relatórios de administração e notas explicativas das empresas que compõe o Índice de Sustentabilidade Empresarial.

A amostra da pesquisa constitui-se de todas as empresas que compõem o Índice de Sustentabilidade Empresarial 2009/2010 da Bovespa. O ISE é formado por companhias de 13 diferentes segmentos da Bovespa e de três níveis de governança corporativa, que correspondem a 24 empresas. As demais classificam-se no nível tradicional da Bovespa, totalizando 29 empresas.

A busca procedeu-se em 58 relatórios, sendo relatórios de administração e notas explicativas do ano de 2008, verificando-se a evidenciação das informações nas empresas que compõem o Índice de Sustentabilidade Empresarial, por meio de um modelo desenvolvido com base nos indicadores de responsabilidade social empresarial do Instituto Ethos (2009), permitindo realizar análise de conteúdo nos relatórios de administração e notas explicativas. Inicialmente quantificam-se os trechos dos RA e NE para identificar as palavras: resíduos, materiais, energia, água e transporte. No Quadro 1 apresenta-se o constructo das estratégias de análise da evidenciação ambiental.

\section{Categoria 1: Resíduos}

1.1 - Gastos com destinação de resíduos ou quantidade de resíduos gerada

1.2 - Projetos para disposição correta de resíduos

1.3 - Projetos de redução da quantidade de resíduos

1.4 - Reaproveitamento dos Resíduos

Categoria 2: Materiais

2.1 - Consumo de materiais novos, escolhas alternativas para reduzir os impactos ambientais

2.2 - Consumo de materiais reciclados

2.3 - Projetos para redução da utilização de materiais de uso e consumo

\section{Categoria 3: Energia}

3.1 - Consumo de energia

3.2 - Fontes alternativas de energia, causando menos impactos ambientais

3.3 - Projetos para redução do consumo de energia

3.4 - Readequação dos ambientes para utilizar mais luz solar

4.1 - Consumo de água

Categoria 4: Água

4.2 - Projetos de redução do consumo de água

4.3 - Estações de tratamento de água

Categoria 5: Transporte

5.1 - Gastos com transporte

5.2 - Programas de incentivo aos transportes de massas

5.3 - Opções alternativas de transporte ambientalmente responsáveis

5.4 - Implantação e utilização de tecnologia para substituição de deslocamento para reuniões

Quadro 1 - Estratégias de análise da evidenciação ambiental

Fonte: Adaptado do Instituto Ethos (2009) 
O modelo utilizado para analisar a gestão ambiental evidenciada nos relatório de administração e notas explicativas integrantes das demonstrações financeiras padronizadas das empresas utilizadas no estudo, divide-se em cinco categorias, Resíduos; Materiais; Energia; Água e Transporte. Buscou-se investigar as ações implementadas pelas empresas que integram o ISE com relação ao consumo de recursos renováveis e não renováveis, ações para redução e melhorias na destinação de resíduos; ações de redução do consumo de materiais; ações de conservação de energia; ações para redução do consumo de água; medidas para reduzir transporte.

Na sequência foi feita a interpretação do trecho no qual a palavra estava inserida, visando identificar se estava relacionada ao contexto da pesquisa. Se fazia parte do contexto da pesquisa, aplicou-se a técnica de análise de conteúdo nos relatórios. Bardin (1977) cita que a técnica de analise de conteúdo prevê estudo de interpretação de textos para compreender a construção de resultados. Não se trata de um instrumento, mas de um apanhado de apetrechos, com maior rigor, será um único instrumento, mas marcado por uma grande disparidade de formas e adaptável a um campo de aplicação muito vasto que são as comunicações (Bardin, 1977).

Após a análise de conteúdo dos RA e NE, os dados coletados foram organizados em quadros, para análise da evidenciação das informações de gestão ambiental. Além disso, alguns relatos mais específicos foram extraídos desses documentos pesquisados para elucidar a evidenciação das informações de gestão ambiental das organizações do ISE.

\section{ANÁLISE DOS DADOS}

A evidenciação das informações nas empresas que compõem o Índice de Sustentabilidade Empresarial procedeu-se por meio de um modelo desenvolvido com base nos indicadores de responsabilidade social empresarial do Instituto Ethos. Explicitando ações ambientais depreendidas pelas empresas foco do estudo, verifica-se a minimização no descarte de resíduos, forma de utilização de recursos naturais não renováveis (como consumo de energia e água), participação de materiais usados provenientes de reciclagem e reutilização de materiais.

O Quadro 2 demonstra a quantidade de organizações que evidenciaram os itens referentes aos Resíduos e participação destas na amostra total.

\begin{tabular}{|l|r|r|r|r|r|r|}
\hline \multirow{2}{*}{ Categoria 1: Resíduos } & \multicolumn{3}{|c|}{$\begin{array}{l}\text { No. de empresas } \\
\text { que evidenciam }\end{array}$} & \multicolumn{2}{c|}{$\begin{array}{l}\text { \% de empresas } \\
\text { que evidenciam/ } \\
\text { Amostra Total }\end{array}$} \\
\cline { 2 - 7 } & RA & NE & Total & RA & NE & Total \\
\hline $\begin{array}{l}1.1 \text { - Gastos com destinação de resíduos ou quantidade } \\
\text { de resíduos gerada }\end{array}$ & 5 & 0 & 5 & $17 \%$ & $0 \%$ & $9 \%$ \\
\hline 1.2 - Projetos para disposição correta de resíduos & 14 & 4 & 18 & $48 \%$ & $14 \%$ & $31 \%$ \\
\hline 1.3 - Projetos de redução da quantidade de resíduos & 12 & 1 & 13 & $41 \%$ & $3 \%$ & $22 \%$ \\
\hline 1.4 - Reaproveitamento dos Resíduos & 8 & 3 & 11 & $28 \%$ & $10 \%$ & $19 \%$ \\
\hline
\end{tabular}

Quadro 2 - Resíduos na gestão ambiental evidenciadas pelas empresas do ISE

Fonte: Dados da pesquisa

Verifica-se que na categoria 1 - Resíduos, predominam as evidenciações por parte das empresas nos relatórios de administração. Em ambas as divulgações percebe-se que o item 1.2 referente aos projetos para disposição correta de resíduos possui maior evidenciação. Nota-se que nos itens 1.2 projetos para disposição correta de resíduos e 1.3 projetos de redução da quantidade de resíduos aparecem mais comumente nas empresas analisadas, representando $48 \%$ e $41 \%$ respectivamente nas organizações estudadas. 
A quantidade de materiais consumidos impacta diretamente no volume de resíduos gerados pela organização e no impacto ecológico gerado pela extração de materiais primários. No sentido de ilustrar a evidenciação no estudo, destacam-se algumas afirmações selecionadas nos relatórios das empresas da amostra, para apresentar os contextos observados na análise de conteúdo, referente aos resíduos, projetos para disposição correta e para redução da quantidade de resíduos.

Certificação ISO 14001 - Relacionada a aspectos ambientais, com destaque para trabalhos de redução da geração de resíduos sólidos de obras civis e do consumo de insumos. O Bradesco foi a primeira Instituição Financeira no Brasil a receber esta Certificação. (Relatório da Administração 2008, Bradesco). [grifo nosso]

Prêmio Fritz Muller. O troféu foi concedido à CELESC Distribuição S.A. pela Fundação do Meio Ambiente de Santa Catarina - FATMA, em reconhecimento ao conjunto de ações desenvolvido pela Empresa no aperfeiçoamento de programas como o de gestão de resíduos e, principalmente, pela conquista do licenciamento ambiental corretivo de seus empreendimentos construídos antes do licenciamento tornarse exigência legal. (Relatório da Administração 2008, CELESC). [grifo nosso]

Denota-se que as empresas por meio de programas relacionados à gestão ambiental vêm desenvolvendo diversos mecanismos que objetivam redução e destinação correta de resíduos, evidenciando tais informações conforme Categoria 1 analisada. No Quadro 3 apresentam-se as evidenciações das empresas do ISE, quanto o item Materiais, quantidade e percentual de empresas considerando a amostra total.

\begin{tabular}{|l|r|r|r|r|r|r|}
\hline \multirow{2}{*}{ Categoria 2: Materiais } & \multicolumn{3}{|c|}{$\begin{array}{l}\text { No. de empresas } \\
\text { que evidenciam }\end{array}$} & \multicolumn{2}{c|}{$\begin{array}{c}\text { \% de empresas } \\
\text { que evidenciam/ } \\
\text { Amostra Total }\end{array}$} \\
\cline { 2 - 8 } & RA & NE & Total & RA & NE & Total \\
\hline $\begin{array}{l}\text { 2.1 - Consumo de materiais novos, escolhas } \\
\text { alternativas para reduzir os impactos ambientais }\end{array}$ & 1 & 0 & 1 & $3 \%$ & $0 \%$ & $2 \%$ \\
\hline 2.2 - Consumo de materiais reciclados & 1 & 3 & 4 & $3 \%$ & $10 \%$ & $7 \%$ \\
\hline $\begin{array}{l}2.3 \text { - Projetos para redução da utilização de materiais } \\
\text { de uso e consumo }\end{array}$ & 1 & 2 & 3 & $3 \%$ & $7 \%$ & $5 \%$ \\
\hline
\end{tabular}

Quadro 3 - Materiais na gestão ambiental evidenciados pelas empresas do ISE

Fonte: Dados da pesquisa

$\mathrm{Na}$ categoria 2 - materiais, não foram encontrados muitos indícios de forte evidenciação. Ocorreu uma divisão acentuada nos meios utilizados pelas empresas para evidenciar as informações referentes aos materiais. A análise aplicada verificou que as empresa evidenciam pouco sobre materiais novos e reciclados, assim, os dados obtidos denotam que sua representatividade nos itens analisados é baixa. Contata-se a que a maioria das companhias do ISE não evidencia este item, todavia, o aspecto Materiais identifica a redução da utilização de materiais resultantes de matéria prima virgem por parte das empresas, além de contribuir para a redução dos custos operacionais da empresa, existindo nesta categoria uma discrepância elevada da teoria e prática.

Quanto às informações divulgadas a respeito dos materiais, destacam-se as seguintes evidenciações: 
Reutilização de materiais de consumo (1): Preocupada em reduzir a compra de materiais, a fim de conservar a base de recursos globais, $\underline{a}$ Light tem utilizado materiais oriundos de reciclagem, com destaque para o grande avanço na quantidade de papel reciclado usada, que chegou a 97\% do total consumido. (Relatório da Administração 2008, Light). [grifo nosso]

Sistema de Gestão Ambiental - SGA, baseado na ISO 14000, que tem permitido o tratamento adequado dos resíduos de óleos, graxas e estopas usadas, materiais que estão sendo destinados a empresas devidamente habilitadas para a reciclagem ou destinação final desses produtos. Outras medidas têm sido adotadas como a utilização de canecas de plástico em substituição a copos descartáveis, reutilização de papel sulfite e a substituição de panos brancos e estopas de limpeza por toalhas recicláveis. (Relatório da Administração 2008, Cesp). [grifo nosso]

Verifica-se que as companhias vêm utilizando materiais oriundos de reciclagem, reduzindo a compra de matérias, substituindo alguns materiais por alternativas que possibilitam gerir recursos mais eficientemente na questão ambiental, ao evidenciarem estas informações demonstram a sociedade sua responsabilidade para tal. Atendendo assim, os itens verificados 2.2 - Consumo de materiais reciclados e 2.3 - Projetos para redução da utilização de materiais de uso e consumo.

A Categoria 3 é evidenciada no Quadro 4, no qual verifica-se a quantidade de organizações que evidenciaram as subcategorias mencionadas e participação na amostra total.

\begin{tabular}{|l|r|r|r|r|r|r|}
\hline \multirow{2}{*}{ Categoria 3: Energia } & \multicolumn{2}{|c|}{$\begin{array}{c}\text { No. de empresas } \\
\text { que evidenciam }\end{array}$} & \multicolumn{2}{|c|}{$\begin{array}{c}\text { \% de empresas } \\
\text { que evidenciam/ } \\
\text { Amostra Total }\end{array}$} \\
\cline { 2 - 7 } & RA & NE & Total & RA & NE & Total \\
\hline 3.1 - Consumo de energia & 7 & 0 & 7 & $24 \%$ & $0 \%$ & $12 \%$ \\
\hline $\begin{array}{l}3.2 \text { - Fontes alternativas de energia, causando menos } \\
\text { impactos ambientais }\end{array}$ & 12 & 6 & 18 & $41 \%$ & $21 \%$ & $31 \%$ \\
\hline 3.3 - Projetos para redução do consumo de energia & 18 & 7 & 25 & $62 \%$ & $24 \%$ & $43 \%$ \\
\hline $\begin{array}{l}3.4 \text { - Readequação dos ambientes para utilizar mais } \\
\text { luz solar }\end{array}$ & 0 & 0 & 0 & $0 \%$ & $0 \%$ & $0 \%$ \\
\hline
\end{tabular}

Quadro 4 - Energia na gestão ambiental evidenciada pelas empresas do ISE

Fonte: Dados da pesquisa

O Quadro 4 apresenta informações quanto a Categoria 3 - Energia., que apresenta-se como uma das categorias mais evidenciadas pelas empresas que compõem o ISE. Destaca-se que as informações evidenciadas sobre energia predominaram nos relatórios de administração. A subcategoria 3.3 - projetos para redução de consumo de energia foi evidenciada em 25 relatórios analisados, item com maior representatividade nesta análise, o que não ocorre com o item 3.4 - readequação dos ambientes internos para utilizar mais luz solar. Este item não foi evidenciado pelas empresas em seus RA e NE. O aspecto Energia monitora o consumo deste bem não renovável e com isso promove uma conscientização e estímulo a adoção de práticas responsáveis no que se refere à eficiência energética, algo essencial na atualidade.

No critério "Energia”, destaca-se uma para ilustrar a análise de algumas evidenciações obtidas no estudo. 
A Companhia também conta com um Sistema de Gestão Ambiental (SGA), implementado em 2000 e estruturado de acordo com as diretrizes da ISO 14001. [...] Por meio do SGA, a companhia mapeou todos os impactos e riscos decorrentes de sua operação e implementou ações gerenciais para prevenção, mitigação e redução dos impactos que podem causar danos ao meio ambiente. As principais medidas são a gestão de resíduos e o monitoramento do consumo de água, energia e combustível. (Relatório da Administração 2008, AES Tiete). [grifo nosso]

Nossas unidades industriais de papel e celulose produzem uma parcela significativa da energia que consomem. Essa energia é gerada por meio de fontes renováveis, como o licor negro (subproduto gerado no processo de cozimento da madeira para extração da celulose) e a biomassa (cascas e cavacos de madeira), e também por meio de fontes não-renováveis, como gás natural e óleo combustível. (Relatório da Administração 2008, Suzano). [grifo nosso]

A gestão ambiental vem sendo adotada em muitas empresas, geralmente é implantada junto com algum projeto ou sistema, visando gerenciar, otimizar, estudar, prevenir e mitigar impactos e riscos decorrentes das atividades da empresa. Neste contexto, a energia como impulsionadora das atividades desenvolvidas ganha importante papel na evidenciação da gestão ambiental, conforme se verifica nas análises desta amostra.

O Quadro 5 apresenta a variável água e o número de empresas do ISE que evidenciaram as subcategorias propostas e a relação no total de empresas analisadas.

\begin{tabular}{|l|r|r|r|r|r|r|}
\hline \multirow{2}{*}{ Categoria 4: Água } & \multicolumn{3}{|c|}{$\begin{array}{c}\text { No. de empresas } \\
\text { que evidenciam }\end{array}$} & $\begin{array}{c}\text { \% de empresas } \\
\text { que evidenciam/ } \\
\text { Amostra Total }\end{array}$ \\
\cline { 2 - 8 } & RA & NE & Total & RA & NE & Total \\
\hline 4.1 - Consumo de água & 1 & 0 & 1 & $3 \%$ & $0 \%$ & $2 \%$ \\
\hline 4.2 - Projetos de redução do consumo de água & 10 & 2 & 12 & $34 \%$ & $7 \%$ & $21 \%$ \\
\hline 4.3 - Estações de tratamento de água/esgoto & 3 & 2 & 5 & $10 \%$ & $7 \%$ & $9 \%$ \\
\hline
\end{tabular}

Quadro 5 - Água na gestão ambiental evidenciadas pelas empresas do ISE

Fonte: Dados da pesquisa

Água demonstra sua importância ao ser analisada pelo risco de escassez de água potável, que pode causar impactos amplos na qualidade de vida, incluindo consequências econômicas. Observa-se que esta categoria, assim como a maioria das outras categorias evidenciadas, contém mais informações evidenciadas nos relatórios de administração. Sua análise possui representatividade quando se verificam todas as empresas do ISE, chegando a $34 \%$ das empresas da amostra no item 4.2 - projetos de redução do consumo de água.

$\mathrm{Na}$ categoria água, buscou-se alguns trechos evidenciados nos relatórios de administração das empresas analisadas.

A unidade Botucatu iniciou em 2008 a construção de uma estação de tratamento de efluentes de alta tecnologia, com baixo consumo de produtos químicos e energia elétrica e com redução na geração de resíduos. Além disso, a água tratada possui elevado potencial de reuso. (Relatório da Administração 2008, EMBRAER). [grifo nosso] 
Em linha com essa busca pela eficiência, conseguimos uma queda de 8,91\% no consumo de água por unidade faturada. Por considerar a água um recurso altamente relevante, não apenas para a Natura, mas para toda a sociedade, planejamos intensificar as ações em torno desse tema a partir de 2009. (Relatório da Administração 2008, Natura). [grifo nosso]

Nota-se que as empresas evidenciam a categoria água, relacionando o item a sobrevivência da sociedade, percebendo que ela, bem como todas as ações ambientais que as empresas tomam, visam o mantimento e a conservação ambiental, agrega valor à empresa e reduz custos desnecessários.

A última categoria analisada é o transporte, apresentado no Quadro 6.

\begin{tabular}{|l|r|r|r|r|r|r|}
\hline \multirow{2}{*}{ Categoria 5: Transporte } & \multicolumn{3}{|c|}{$\begin{array}{c}\text { No. de empresas } \\
\text { que evidenciam }\end{array}$} & \multicolumn{2}{c|}{$\begin{array}{c}\text { \% de empresas } \\
\text { que evidenciam/ } \\
\text { Amostra Total }\end{array}$} \\
\cline { 2 - 9 } & RA & NE & Total & RA & NE & Total \\
\hline 5.1 - Gastos com transporte & 5 & 0 & 5 & $17 \%$ & $0 \%$ & $9 \%$ \\
\hline 5.2 - Programas de incentivo aos transportes de massas & 0 & 0 & 0 & $0 \%$ & $0 \%$ & $0 \%$ \\
\hline $\begin{array}{l}\text { 5.3 - Opções alternativas de transporte ambientalmente } \\
\text { responsáveis }\end{array}$ & 1 & 0 & 1 & $3 \%$ & $0 \%$ & $2 \%$ \\
\hline $\begin{array}{l}\text { 5.4 - Implantação e utilização de tecnologia para } \\
\text { substituição de deslocamento para reuniões }\end{array}$ & 0 & 0 & 0 & $0 \%$ & $0 \%$ & $0 \%$ \\
\hline
\end{tabular}

Quadro 6 - Transporte na gestão ambiental evidenciado pelas empresas do ISE

Fonte: Dados da pesquisa

Dentre as categorias analisadas, a Categoria 5 - Transporte está menos relatada nos relatórios analisados. Foi evidenciado nos relatórios de administração, somente o item, 5.1 gastos com transporte em 5 empresas. A baixa obtenção de evidenciação dos itens analisados na categoria Transporte revela pouca representatividade do item na amostra analisada. A categoria possui o objetivo de vislumbrar se as empresas envolvem-se em ações buscando a redução de transportes, através de uso de tecnologias para substituição de deslocamentos, ou uso alternativo de transporte e de transporte de massas.

Na Categoria 5 - Transporte, apresenta-se a subcategoria 5.1 - gastos com transporte evidenciada nas empresas nos relatório de administração. Cabe mencionar que os gastos com transporte analisados referem-se aos valores específicos evidenciados nos relatórios de administração, normalmente apresentados em tabela especifica de divulgação de gastos com ações ambientais, demonstrando o custo com transportes.

O Quadro 7 permite a análise das cinco categorias investigadas de acordo com o modelo desenvolvido com base nos indicadores de responsabilidade social empresarial do Instituto Ethos (2009).

\begin{tabular}{|c|c|c|}
\hline $\begin{array}{r}\text { It } \\
\text { viden }\end{array}$ & 5 & $\begin{array}{c}\text { Total de } \\
\text { empresas }\end{array}$ \\
\hline RA & $\mathrm{NE}$ & Quant. \\
\hline
\end{tabular}




\begin{tabular}{|l|r|r|r|r|}
\hline Categoria 1: Resíduos & 39 & 8 & 19 & $66 \%$ \\
\hline Categoria 2: Materiais & 3 & 5 & 4 & $14 \%$ \\
\hline Categoria 3: Energia & 37 & 13 & 18 & $62 \%$ \\
\hline Categoria 4: Água & 14 & 4 & 13 & $45 \%$ \\
\hline Categoria 5: Transporte & 5 & 0 & 5 & $21 \%$ \\
\hline Total & $\mathbf{9 8}$ & $\mathbf{3 0}$ & - & - \\
\hline
\end{tabular}

Quadro 7 - Categorias de gestão ambiental evidenciadas pelas empresas do ISE

Fonte: Dados da pesquisa

Denota-se que a Categoria 1 - Resíduos e a Categoria 3 - Energia são as categorias mais evidenciadas pelas empresas que compõem o Índice de Sustentabilidade empresarial, predominando os itens de projetos para: disposição correta de resíduos, redução de resíduos e redução do consumo de energia. Resíduos e Energia cada categoria corresponde a mais de $60 \%$ das empresas que analisadas no estudo evidenciaram alguns itens requeridos, sendo respectivamente 66\% e 62\%,. Na sequência encontra-se a Categoria 4 - Água com 45\% das empresas que evidenciaram algum dos itens analisados. Com evidenciação menos expressivas encontram-se Transporte e Materiais, com 21\% e 14\% respectivamente, nas duas categorias as evidenciações das empresas que compõem o ISE acumulam 13 itens em nove empresas.

Verifica-se ainda que ao observar 5 categorias e 18 subcategorias em 29 relatórios de administração e 29 notas explicativas, a possibilidade máxima seria de 1.044 observações. A pesquisa chega a 128 observações que correspondem a 12\% do total possível de evidenciação ambiental nas empresas que compõem o ISE, com base no modelo proposto. A baixa evidenciação de questões de gestão ambiental corrobora com os resultados do estudo de Leite, Ribeiro e Pacheco (2007) onde observaram que a evidenciação referente a passivos ambientais e interações com o meio ambiente nos relatórios de administração e notas explicativas vêm sendo apresentados com poucos detalhes e pequeno grau de evidenciação.

\section{CONCLUSÕES}

O estudo objetivou analisar as informações relacionadas à gestão ambiental mais evidenciadas nos relatórios de administração e notas explicativas das empresas que compõe o Índice de Sustentabilidade Empresarial. Para atender ao objetivo central foi desenvolvido um modelo com base nos indicadores de responsabilidade social empresarial do Instituto Ethos, permitindo analisar a evidenciação da gestão ambiental nos relatórios utilizados.

Com relação às informações mais evidenciadas nas companhias que compõem o Índice de Sustentabilidade Empresarial, verificou-se que a Categoria 1 - Resíduos e a Categoria 3 - Energia são as mais evidenciadas, cada categoria corresponde a mais de $60 \%$ das empresas analisadas no estudo evidenciaram alguns itens requeridos. Os subitens de projetos para disposição correta de resíduos, projetos para redução de resíduos e projetos para redução do consumo de energia, são os mais evidenciados pelas empresas do ISE.

No que diz respeito às demais categorias, Água corresponde a Categoria 4, e soma $45 \%$ das empresas que evidenciaram algum dos itens analisados. As Categorias 2 - Materiais e Categoria 5 - Transportes, não ultrapassam 21\% o primeiro e 14\% o segundo de empresas que evidenciaram os itens analisados referentes à gestão ambiental.

Com base nas observações realizadas por meio de análise de conteúdo nas companhias que compõem o ISE, verificou-se que a possibilidade máxima de evidenciação ambiental seria de 1044 observações impostas pelo modelo utilizado e pelos relatórios analisados. Este estudo chegou a 128 observações que correspondem a 12\% do total possível de evidenciação ambiental nas empresas que compõem o ISE considerando o modelo desenvolvido a partir dos indicadores de responsabilidade social empresarial do Instituto Ethos. 
Conclui-se que as informações de gestão ambiental mais evidenciadas pelas empresas que compõem o ISE referem-se a "Resíduos" e a "Energia". Infere-se que os achados evidenciados nesta pesquisa denotam pouca evidenciação dos itens analisados por meio do modelo utilizado, tendo pouca representatividade quando comparado às possibilidades apresentadas pelo modelo. Neste sentido, por serem empresas que fazem parte de um índice que considera questões ambientais na escolha das empresas participantes, acredita-se que a evidenciação de informações de gestão ambiental deva ser mais comumente explicitada nestes relatórios, que servem como fontes de informação na tomada de decisão dos diversos usuários.

Devido às limitações do estudo, recomenda-se a realização de uma pesquisa englobando empresas que não façam parte do Índice de Sustentabilidade Empresarial da Bovespa, a fim de verificar diferenças de evidenciação de informações sobre gestão ambiental.

\section{REFERÊNCIAS}

Aquino, W.; Santana, A. C. (1992). Evidenciação. Caderno de Estudos, São Paulo: FIPECAFI n. 5, p. jun.

Andrade, R.; Tachizawa, T. E Carvalho, A.B. (2002). Gestão ambiental: enfoque estratégico aplicado ao desenvolvimento sustentável. São Paulo, Makron Books, p. 246.

Azevedo, Tânia C.; Cruz, Cláudia F. (2006). Balanço Social como instrumento para demonstrar a responsabilidade social das entidades: Uma discussão quanto à elaboração, padronização e regulamentação. Revista Pensar Contábil, v.8, p.13-20.

(2007). Evidenciação das informações de natureza sócio-ambiental divulgadas pelas distribuidoras de energia elétrica que atuam na região nordeste do Brasil e sua relação com indicadores de desempenho empresarial. In: Congresso Brasileiro de Custos, 14., 2007. João Pessoa-PB. Anais... João Pessoa-PB: CBC, CD-ROM.

Bardin, Laurence. (1977). Analise de conteúdo. Lisboa: Edições 70, 225p.

Beuren et al. (2008). Como Elaborar Trabalhos Monográficos em Contabilidade. 3 ed., São Paulo: Atlas.

Bolsa De Valores De São Paulo (Bovespa). Disponível em: <www.bovespa.com.br>. Acesso em: 03 de setembro de 2009.

ISE - Índice de Sustentabilidade Empresarial. Disponível em: <www.bovespa.com.br>. Acesso em: 03 de setembro de 2009.

Borba, José Alonso; Alves, Jorge Luís; Rover, Suliani. (2005). Análise do conteúdo ambiental das demonstrações contábeis publicadas no Brasil e nos Estados Unidos: um estudo nas companhias com ADR nível III. In: Congresso USP de Controladoria e Contabilidade, 5., 2005. São Paulo. Anais... São Paulo: FEA/USP. CD-ROM.

Burlin, L. R. et al. (2001). Relatório da administração: uma análise exploratória de suas informações no aspecto qualitativo. In: Seminário USP de Contabilidade, 1., 2001, São Paulo. 
Anais... São Paulo: FEA/USP. CD-ROM.

Calixto, Laura. (2006). Uma análise da evidenciação ambiental de companhias brasileiras - de 1997 a 2005. In: Congresso Brasileiro de Custos, 13., 2006. Belo Horizonte. Anais...Belo Horizonte: CBC. CD-ROM.

Campbell, David. (2004). A longitudinal and cross-sectional analysis of environmental disclosure in UK companies - a research note. The British Accounting Review, n.36, p.107117.

Garcia, Regis et al. (2008). Contabilidade ambiental e sustentabilidade empresarial: estudo das empresas do ISE - BOVESPA. Congresso Brasileiro de Custos. 15., 2008. Curitiba. Anais...Curitiba: CBC.CD-ROM.

Gonçalves, S.S., Heliodoro, P.A.A. (2005). Contabilidade ambiental como um novo paradigma. Revista Universo Contábil, n.1, p. 84-96.

Gonçalves, R. C. M. G.; Pirani, D. C.; Borger, F. G. (2007). Qualidade das Informações sobre Responsabilidade Social Divulgadas pelos Bancos Privados com Ações Listadas no Índice de Sustentabilidade Empresarial da Bovespa. In: Encontro Nacional da Associação de PósGraduação e Pesquisa em Administração, 31, Rio de Janeiro. Anais... Salvador: ANPAD, 2007. CD-ROM.

Instituto Ethos. Indicadores Ethos de responsabilidade social empresarial. 2009. Disponível em: www.ethos.org.br Acesso 18. Ago.2009.

Iudícibus, Sérgio de. (1997). Teoria da contabilidade. 5. ed. São Paulo: Atlas, 1997.

Moura, Luiz Antônio Abdalla de. (2008). Qualidade e Gestão ambiental: sustentabilidade e implantação da ISSO 14.001. 5. ed. São Paulo: Editora Juarez de Oliveira, 2008.

Moreira, Maria Suely. (2006). Estratégia e implantação do sistema de gestão ambiental: modelo ISO 14.000. Nova Lima: INDG Tecnologia e Serviços Ltda.

Oliveira, Marcelle Colares; Ribeiro, Maísa de Sousa. (2003). Análise da evolução de informações econômico-financeiras de natureza ambiental: o estudo do caso Petrobrás. In: Congresso Brasileiro de Custos, 10., 2003. Guarapari-ES. Anais...Guarapari: CBC, CD-ROM.

Ponte, V. M. R.; Oliveira, M. C. (2004). A prática da evidenciação de informações avançadas e não obrigatórias nas demonstrações contábeis das empresas brasileiras. Revista Contabilidade \& Finanças. São Paulo: USP, n. 36, p. 7-20. set./dez.

Quintas, Tiza T.; Czesnat, Aline de Oliveira; Fernandes, Francisco Carlos. (2008). Panorama de Boas Práticas em Governança Corporativa: uma abordagem sobre a metodologia de gerenciamento de riscos adotada pelas empresas listadas na Bovespa. In: SEMEAD, 11., 2008, São Paulo. Anais... São Paulo: SEMEAD, CD-ROM.

Raupp, Fabiano Maury. Beuren, Ilse Maria. (2008). Caracterização da Pesquisa em Contabilidade. In. Beuren, Ilse Maria (Org). Como elaborar trabalhos monográficos em contabilidade: teoria e prática. 3. ed. São Paulo: Atlas. 
Rezende, I. A. C.; Santos, L. S. R. (2006). Análise da Rentabilidade e Performance dos Investimentos Socialmente Responsáveis: um estudo empírico no mercado brasileiro. In: Encontro da Associação Nacional de Pós-Graduação e Pesquisa em Administração, 30., 2006, Salvador. Anais... Salvador: EnANPAD. CD-ROM.

Rezende, Idália Antunes Cangussú; Nunes, Julyana Goldner; Portela, Simone Salles. (2008). Um estudo sobre o desempenho financeiro do índice Bovespa de Sustentabilidade Empresarial. Revista de Educação e Pesquisa em Contabilidade. Vol. 2, n. ${ }^{\circ}$ 4, Art. 4, pp. 93122.

Ribeiro, Maisa de Souza. (2005). Contabilidade ambiental. São Paulo: Saraiva.

Richardson, Roberto Jarry. (1989). Pesquisa Social: métodos e técnicas. 2. ed. São Paulo: Atlas, 1989.

Rover, Suliani; Borba, José Alonso; Borget, Altair. (2008) Como as Empresas Classificadas no Índice de Sustentabilidade Empresarial (ISE) Evidenciam os Custos e Investimentos Ambientais? Revista de Custos e @gronegócio online.v.4, n.1-jan/abr.

Rover, Suliani Et al. (2009). Explicações para a divulgação voluntária ambiental no Brasil utilizando análise de regressão em painel. In: Congresso Associação Nacional dos Programas de Pós-Graduação em Ciências Contábeis, 3., 2009, São Paulo. Anais... São Paulo: ANPCONT, CD-ROM.

Silveira, Natani Carolina. (2008). Aplicação dos indicadores de responsabilidade social empresarial: estudo de caso com uma empresa de economia de comunhão. 2008. $226 \mathrm{f}$. Dissertação de Mestrado. Universidade de São Paulo. Faculdade de Economia, Administração e contabilidade de Ribeirão Preto.

Souza, R.S.. Evolução e condicionantes da gestão ambiental nas empresas. (2002). REAd Revista Eletrônica de Administração, 8(6):85-112.

Souza, Valdiva R.; Ribeiro, Maisa de S. (2004). Aplicação da contabilidade ambiental na indústria madeireira. Revista de Contabilidade \& Finanças - USP. São Paulo, n. 35, p. 54-67.

Triviños, A. N. S. (1987). Introdução à pesquisa em ciências sociais: a pesquisa qualitativa em educação. São Paulo: Atlas. 175 p.

Valle, Ciro Eyer do. (2004). Qualidade ambiental: ISSO 14.000. 5. ed. São Paulo: Editora Senac São Paulo.

Vaz, A. C.; et al. (2008). Análise comparativa sobre informações voluntárias divulgadas: o social disclosure das empresas latino-americanas listadas na Nyse. In: Encontro da Associação Nacional de Pós-Graduação e Pesquisa em Administração, 32., 2008, Rio de Janeiro. Anais... Rio de Janeiro: ANPAD. CD-ROM.

Wernke, R. (2001). Custos ambientais: uma abordagem teórica com ênfase na obtenção de vantagem competitiva. Revista de Contabilidade do CRC-SP, 5(15):40-49. 